\title{
Comparative Characteristics of the Developed Electric Heat Exchanger Regulators to Obtain the Energy of Water-Ice Phase Transition
}

\author{
${ }^{1}$ Ershova Irina, ${ }^{2}$ Vasilyev Alexey, ${ }^{3}$ Samarin Gennady, ${ }^{4}$ Normov Dmitry, ${ }^{5}$ Zhukov Alexander, ${ }^{6}$ Aleksandrova Galina, \\ ${ }^{7}$ Filippova Irina \\ ${ }^{1-3}$ Federal Scientific Agroengineering Center VIM, Russian Federation, Moscow, 1-y Institutsky Proezd, 5 \\ ${ }^{4}$ Kuban State Agrarian University named after I.T. Trubilin, Russian Federation, Krasnodar Region, Kalinina St., 13 \\ ${ }^{5}$ Federal State Budgetary Educational Institution of Higher Education «State Agricultural Academy of Velikie Luki», \\ Russian Federation, Pskov Region, Velikie Luki, Lenin Aven., 2 \\ ${ }^{6-7}$ Federal State Budgetary Educational Institution of Higher Education «Chuvash I. Yakovlev State Pedagogical \\ University») \\ Email:eig85@yandex.ru
}

Received: $23^{\text {rd }}$ July 2019, Accepted: $10^{\text {th }}$ August 2019, Published: $3^{\text {st }}$ August 2019

\begin{abstract}
The authors have developed electric regulators: relay-pulse ones, with solid filler and electric heater, with solid filler and thermoelectric module, for a heat exchanger to obtain the energy of the water-ice phase transition.

Experimental studies were carried out, the static and dynamic characteristics of electrical controllers were determined to determine the most fast-acting regulator. They substantiated that after the use of the thermoelectric module, the regulator operation is ensured during potato storage heating and cooling. Moreover, when they change the potato storage operating modes by changing the polarity of the thermoelectric module, the speed of the regulatory body is ensured. The heating efficiency of the solid-filled electrical regulator and thermoelectric module is higher than of electrical regulator with solidfilled electrical controller and electric heater.
\end{abstract}

\section{Keywords}

Energy of Phase Transition Water-Ice, Heat Exchanger, Heat-Exchanging Equipment, Electrical Regulator, Electric Controller with Solid Filler and Thermoelectric Module, Heating of an Agricultural Object, Vegetable Storage

\section{Introduction}

Various energy-saving technologies using renewable energy sources [1, 2, 3, 4], electro-hydraulic effect [5], microwave technologies $[6,7,8,9]$ are used for agricultural facilities. The analysis of the literature data has shown the feasibility of water-ice phase transition energy use [10].

They developed the heat exchanger of the experimental unit, by which they maintain the necessary temperature parameters of the vegetable storage. They determined the theoretical parameters of the modernized electric regulators, which make it possible to maintain the required microclimate parameters of the vegetable storehouse through the distribution of the energy carrier to the condenser and to the additional evaporator of the heat exchanger.

\section{Main Focus of the Chapter}

They developed the modernized electric regulators: pulse-relay (Figure 1) [11], with solid filler and electric heater (Figure 2) [12], with solid filler and thermoelectric module (Figure 3) [13]. These regulators are developed for a heat exchanger to obtain ice water phase transition energy.

Figure 1 shows the working sample of a relay-pulse regulator, which is connected to SURI and PBR-3, tested at LLC "Slava Kartofelyu" agriculatural farm and at Cheboksary branch of "UniMilk Company". 

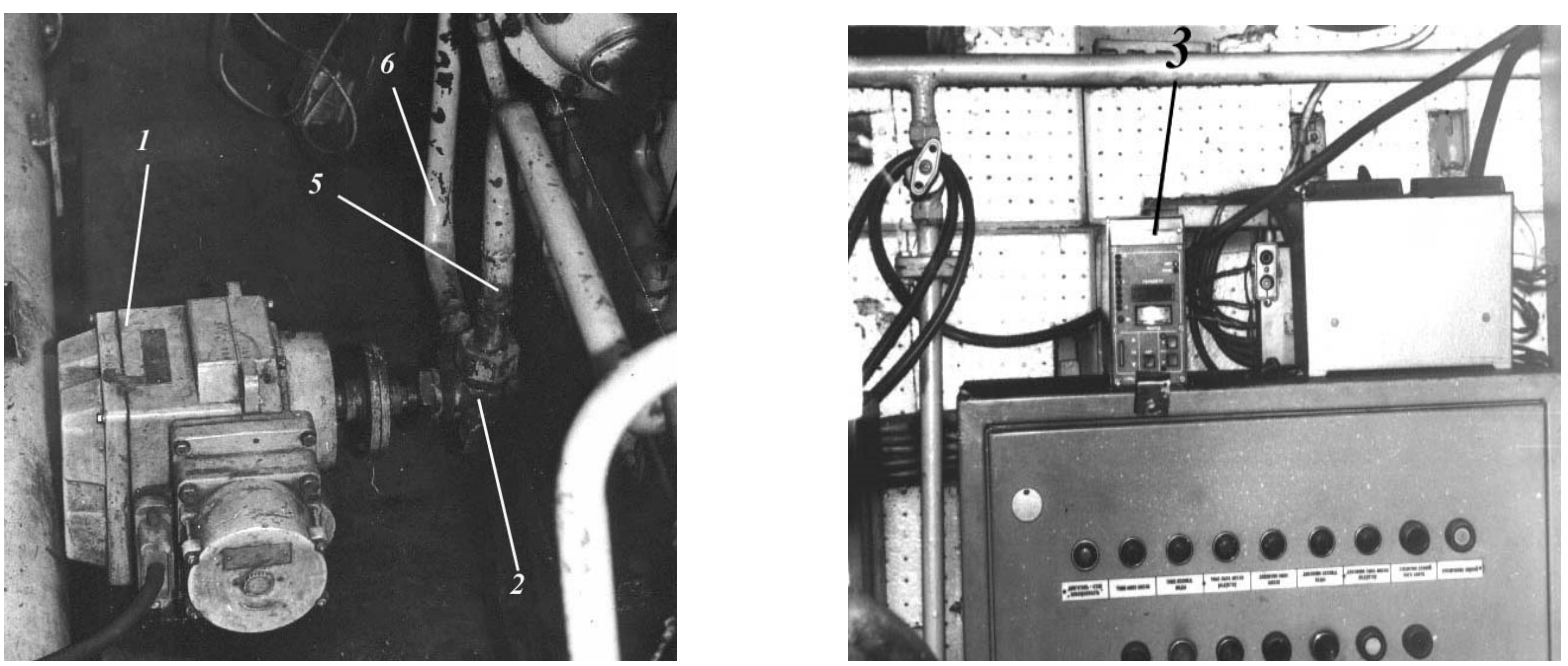

Figure 1: General View of the Relay-Pulse Regulator

(1: Actuator; 2: Regulatory Mechanism; 3: Electronic Control Unit ("SURI", PBR-3); 5, 6: Energy Carrier Channels from the Heat Pump to the Regulatory Body; to the Potato Storage; to the Heating Object, respectively)

Below they presented the sample of an electric regulator with a solid filler and an electric heater (EH) (Fig. 2).

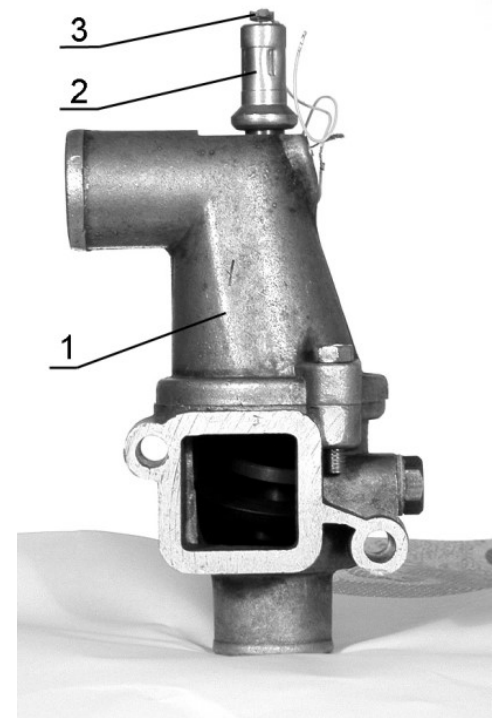

Figure 2 - Electric Regulator with Solid Filler and EH

[1: Housing, 2: Thermo-Power Sensor, 3: Electric Heater (Posistor)]

There is the sample of an electric controller with a thermoelectric module (TM) below [14, 15] (Fig. 2). 


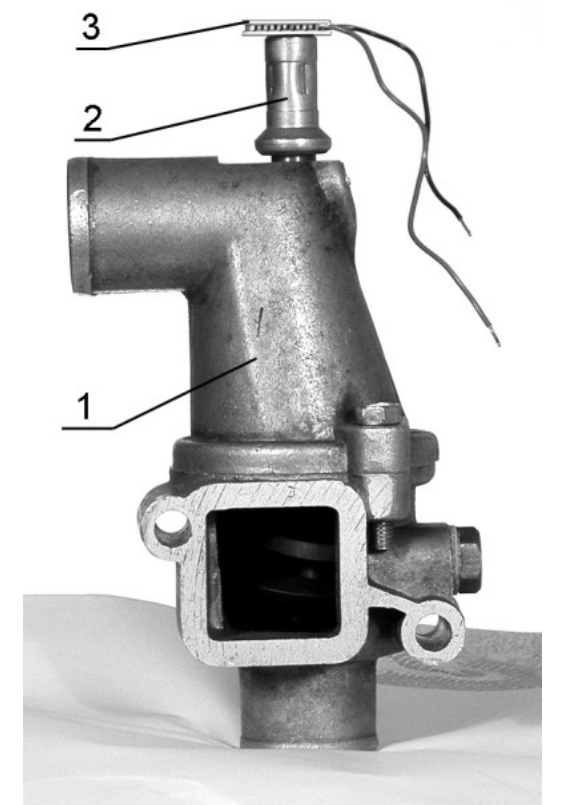

Figure 3 - Electric Regulator with TM

(1: Case, 2: Thermo-Power Sensor, 3: TM)

They studied the dependence of the rod displacement in various designs of actuators (with solid filler; with solid filler and electric heater; with solid filler and thermoelectric module) in the static mode (Fig. 4).

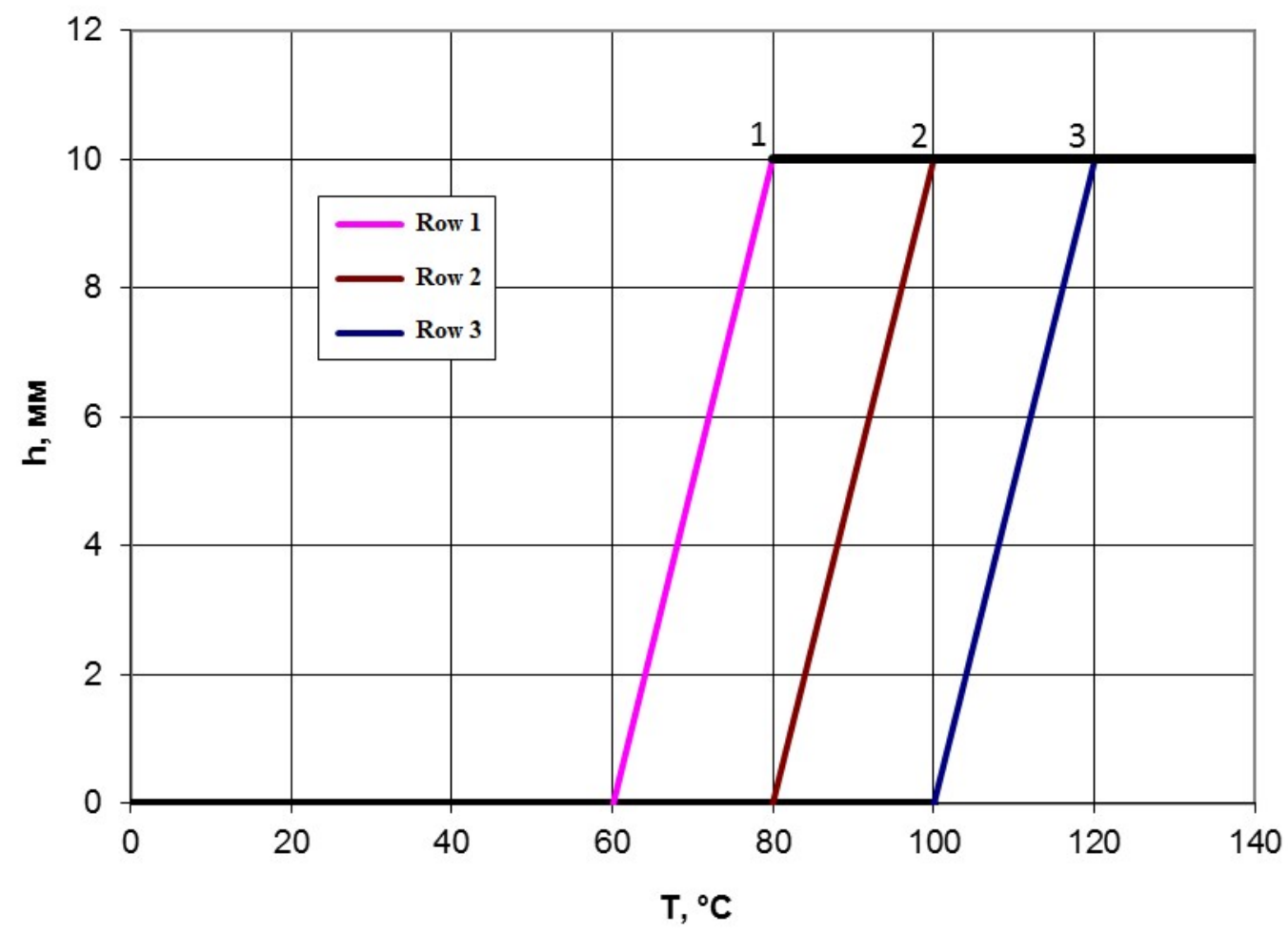

Figure 4: Static Characteristics of Electrical Regulators:

(1: with solid filler and EH; 2: with solid filler; 3: with solid filler and TM)

The study results of the static characteristics of electrical regulators show that the use of heating elements: an electric heater (EH), a thermoelectric module (TM) (graph 1,3) allows you to shift the temperature operation mode in relation to a regulator containing only solid filler (the 2nd graph). 
Experimental studies were carried out with an electric regulator sample, the installation diagram using the example of the regulator with solid filler and TM is shown in Figure 5. In this case, the following were determined: 1) the opening time of the regulator valve; 2) regulator operation modes. Based on the results of the studies, the dynamic characteristics of electrical regulators are developed.

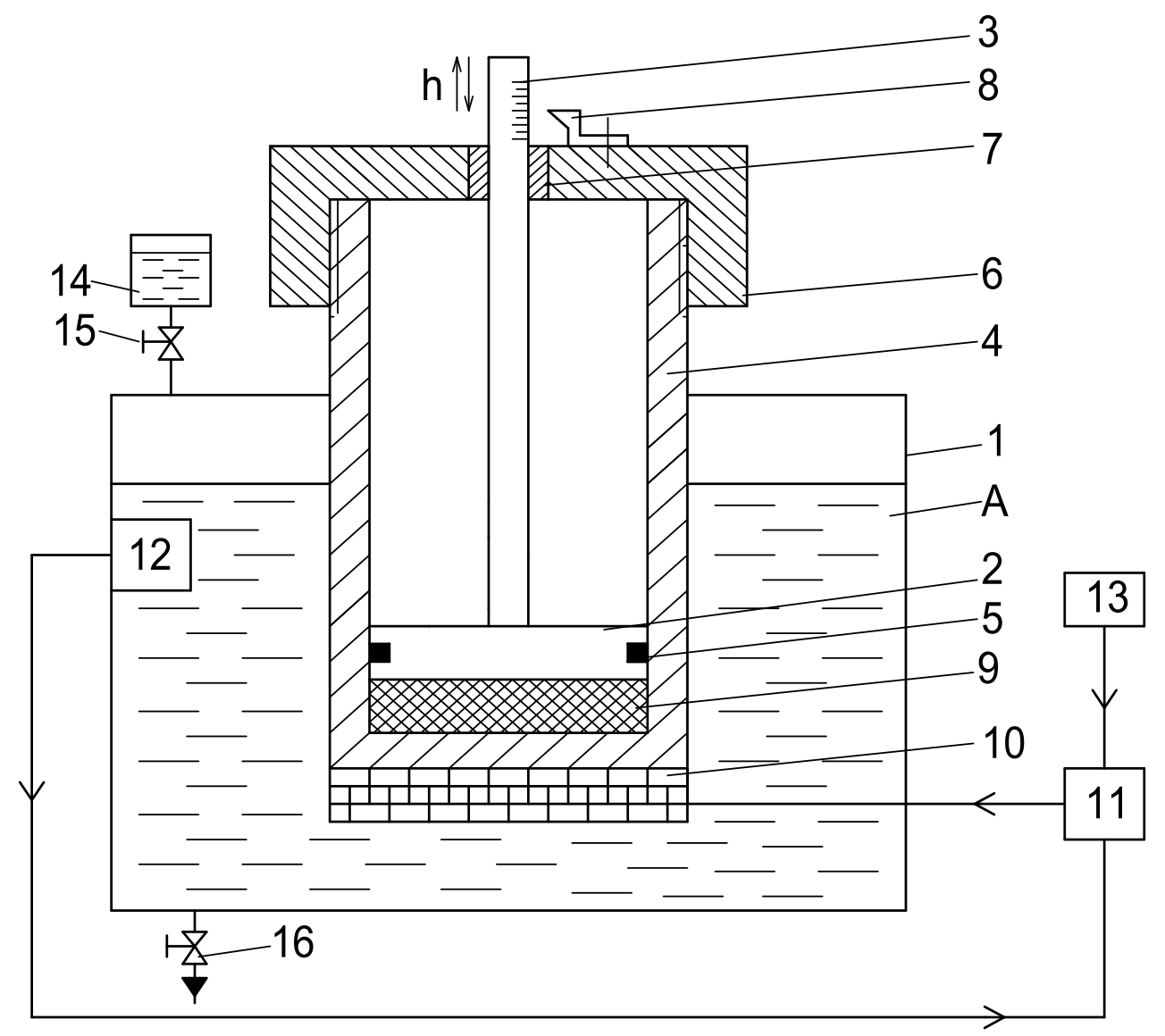

Figure 5: The Scheme of of the Electric Regulator Experimental Unit

( 1: Unit Capacity Housing; 2: Piston; 3: Rod; 4: Cylinder; 5: Sealing Ring; 6: Cover; 7: Guide Bush; 8: Pointer; 9: Solid Filler; 10: TM; 11: Control Unit; 12:Temperature Sensor; 13: Load Sensor; 14: Supply Tank, 15, 16: Valves; A - Installation Tank)

The analysis of the dynamic characteristics of electric regulators is shown on Figure 6 .

\begin{tabular}{|c|c|c|}
\hline Name & \multicolumn{2}{|c|}{$\begin{array}{l}\text { Heating mode (valve opening). Bath water temperature } \\
\left(T_{\text {bath }}\right) 85^{\circ} \mathrm{C}\end{array}$} \\
\hline $\begin{array}{c}\text { Solid filler } \\
\text { regulator } \\
\text { (industrial } \\
\text { thermostat } \\
{[16] \text { ) }}\end{array}$ & 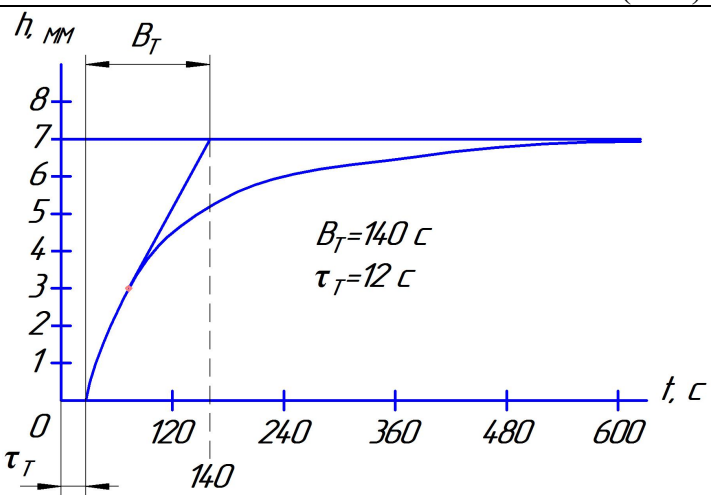 & \\
\hline & $\begin{array}{c}\text { Heating mode (valve opening). Bath water } \\
\text { temperature } \\
\left(\mathrm{T}_{\text {bath }}\right) 85^{\circ} \mathrm{C}\end{array}$ & $\begin{array}{c}\text { Cooling mode (valve closure). Bath water } \\
\text { temperature } \\
\left(\mathrm{T}_{\text {bath }}\right) 4^{\circ} \mathrm{C}\end{array}$ \\
\hline
\end{tabular}




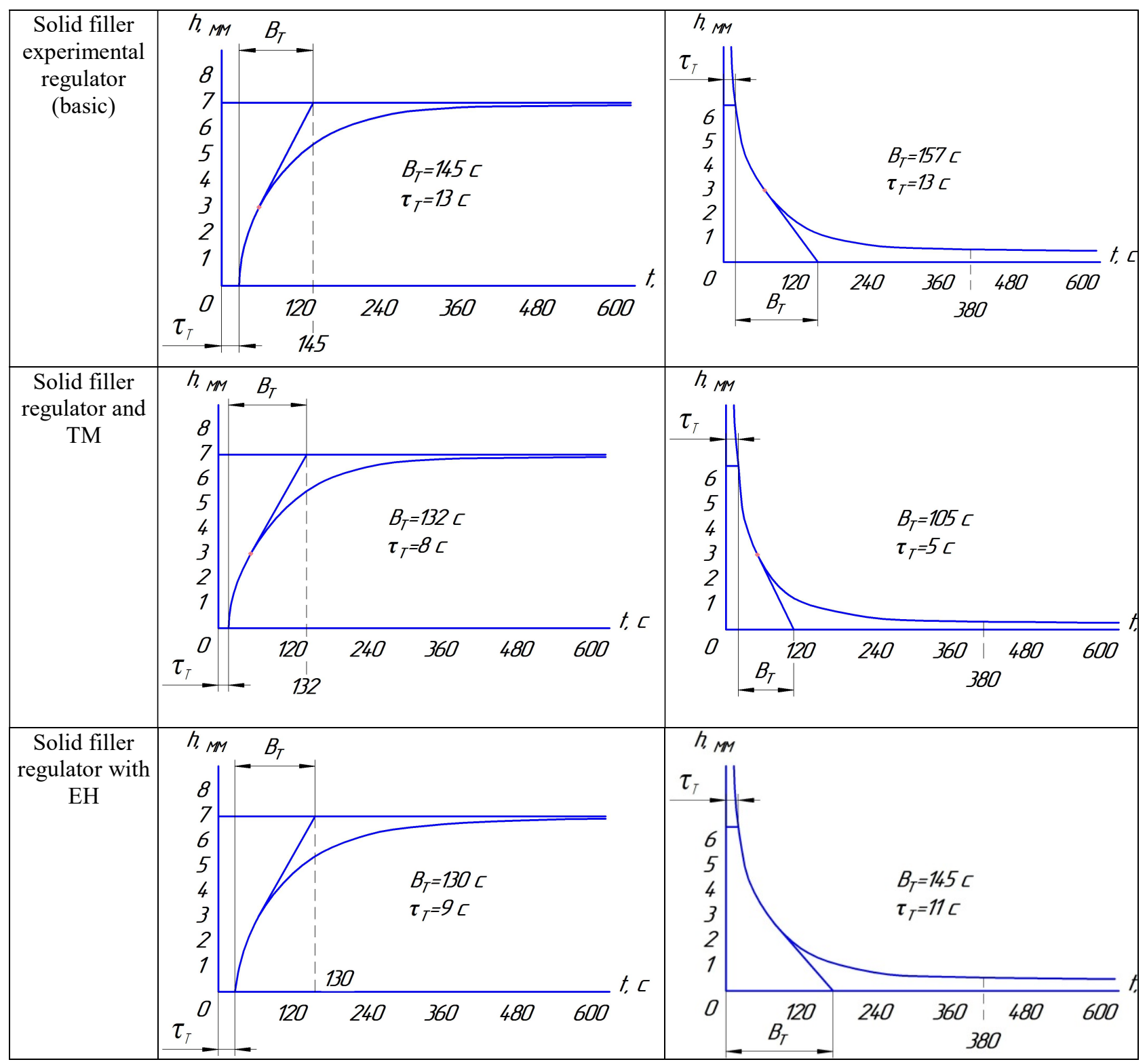

Figure 6: The Analysis of Electrical Regulator Dynamic Characteristics: $B_{\mathrm{r}}-$ Time Constant, $s$; $\tau_{\mathrm{r}}$ - Delay Time, $s$

Thus, the electric and thermoelectric heating elements with speed, can maintain the temperature of the potato storage air effectively. Besides, the location of an electric heater and a thermoelectric module outside the energy medium provides the ease of electric regulator installation, operation and repair [17].

The developed electric regulators are intended for use in a heat exchanger design to obtain the energy of the water-ice phase transition.

\section{Conclusion}

1. Upgraded electric regulators allow to maintain the microclimate of the vegetable storehouse through the distribution of an energy carrier to a condenser and to an additional evaporator of a heat exchanger.

2. The static characteristics of the upgraded electrical regulators determined the working temperature of the solid filler: the minimum $\left(50-60{ }^{\circ} \mathrm{C}\right)$ - with an electric heater, and the maximum $\left(70-80{ }^{\circ} \mathrm{C}\right)$ - with a thermoelectric module.

3. Using the dynamic characteristics of the modernized regulators their performance was compared. In the heating mode, the delay time of regulator valve opening with a thermoelectric module makes 8 seconds, with an electric heater - 9 seconds, of industrial thermostat (basic) - 12 seconds, of the regulator without a heating element - 13 seconds. In cooling mode, the closing time of the regulator valve closure with the thermoelectric module makes $5 \mathrm{~s}$., of the regulator without a heating element - $13 \mathrm{~s}$., of the regulator with an electric heater - $11 \mathrm{~s}$.

4. The heating efficiency of a solid-filled electrical regulator and a thermoelectric module is higher than the solid-filled electrical regulator with electric heater. 


\section{Conflict of Interest}

The authors confirm that the provided data do not contain the conflict of interests.

\section{References}

[1] Belova, M. V., Novikova G. V., Ershova I. G., Ershov M. A. \& O. V. Mikhailova (2006)/ Innovations in Technologies of Agricultural Raw Materials Processing / ARPN Journal of Engineering and Applied Sciences. T. 11. C. 1269-1277/

[2] Patent 2285872, F25B30 / 02. Heat pump / I. V. Moskalenko, A. M. Kostin; publ. 10/20/2006, Bul. No. 29.

[3] Vasiliev A., Ershova I., Belov A., Timofeev V., Uhanova V., Sokolov A. \& Smirnov A. (2018). Energy-saving system development based on heat pump / Amazonia Investiga. - Vol. 7. No 17. - P. 219-227.

[4] Izmailov A. Yu., Dorokhov A. S., Vershinin V. S., Gusarov V. A., Mayorov V. A., Saginov L. D. Photoelectric charger of lithium battery, mounted in the vertical leaf of the window frame. Powerman. 2019. No. 1. C. 20-24.

[5] Belov, A. A. (2018). Modeling the assessment of factors influencing the process of electro-hydraulic water treatment. VESTNIK NGIEI, 11, 103-112.

[6] Rodionova A. V., Borovkov M. S., Ershov M. A. (2012). Justification of the selected frequency of electromagnetic radiation in physical prophylaxis of harbols. NIVA POVOLZ,A, 2012, 1, pp. 108-110

[7] Ershova, I. G., Belova, M. V., Poruchikov, D. V., Ershov, M. A. (2016). Heat treatment of fat-containing raw materials with energy of electromagnetic radiation / International research journal. - No 09(51). - pp. 38-40

[8] Vasiliev A. N., Budnikov D. A., Vasiliev A. A. (2016). Modeling the process of heating the grain in the microwave field of a universal electrical module with various algorithms of electrical equipment // Bulletin of Agrarian Science Don, 2016, Vol. 1. No 33. pp. 12-17.

[9] Ershova I. G. Heat treatment of fat-containing raw materials with energy of electromagnetic radiation / I. G. Ershova, M.V. Belova, D. V. Poruchikov, M.A. Ershov // International research journal, 2016. - No. 09(51). - C. 38-40.

[10] Vasilev A. N., Tutunina E. V. The Results of a preliminary experimental verification of the utilization of low temperature heat transfer fluids in the heat pumps work // Bulletin of agricultural science of the don. - No. 3 (43). - 2018. P. 62-67.

[11] Ershova I. G., Ershov M. A., Poruchikov D. V. Investigation of the relay-pulse regulator of the heat pump. VI international scientific and practical conference "Society of the XXI century: results, challenges, prospects": Sbornik nauchnih trudov (30.09.2017), Stavropol: Logos, 2017, pp. 50-53.

[12] Ershova I. G., Ershov M. A., Poruchikov D. V. Investigation of the electric regulator with a solid filler and an electric heater of the heat pump. VI international scientific and practical conference "Society of the XXI century: results, challenges, prospects": Sbornik nauchnih trudov (30.09.2017), Stavropol: Logos, 2017, pp. 50-56.

[13] Ershova I. G., Ershov M. A., Poruchikov D. V. Modernization of the electric controller with solid filler and thermoelectric heat pump module. International scientific and practical conference "the Impact of the scientific and technological revolution on the nature of the connection between science and production»: Sbornik statey (05.10.2017, Chelyabinsk), - Ufa: Aeterna, 2017. - pp. 43-45.

[14] Drabkin, I. A., Bulat L. P. (2002). Characteristics of thermoelectric modules. Thermoelectric cooling / I. A. Drabkin, L. P. Bulat. - SPb: SPbGuniPT, 2002. - pp. 99-101.

[15] Timofeev V. N. The Use of Thermoelectric Coolers in ICE Cooling Systems. - Cheboksary: Chuvash. state University, 1998. - 5 p.

[16] Patent 2270923 RF, IPC F01P7 / 16. Electric thermostat / V.N. Timofeev, N.P. Kuzin, A.N. Krasnov; publ. 27.02.2006.

[17] Dorokhov A. S. Efficiency assessment of the quality of agricultural machinery and spare parts // Bulletin of the Federal State Educational Institution of Higher Professional Education Moscow State Agroengineering University named after V.P. Goryachkina. No 1 (65), 2015. - pp. 31-35. 